\title{
NEURAL NETWORK MODELING OF SCOUR CONE GEOMETRY AROUND OUTLET IN THE PRESSURE FLUSHING
}

\section{S. EMAMGHOLIZADEH}

Received: 09/11/10

Accepted: 18/04/12

\author{
Department of Water and Soil, Agriculture Collage \\ Shahrood University of Technology \\ Shahrood, Iran
}

\section{ABSTRACT}

When flushing carry out as pressure condition, a scour cone is performed around the outlet. As the flow around the outlet in the pressure flushing is three dimensional, therefore that it is difficult to establish a general empirical model to provide accurate estimation for scour cone volume and length. In this study artificial neural network (ANN) with multi-layer perception which using backpropagation algorithm (MLP/BP) was used. The scour cone volume $\left(V_{f}\right)$ and length $\left(L_{f}\right)$ were modeled as a function of three variables; water depth $\left(\mathrm{H}_{\mathrm{W}}\right)$, mean flow velocity through outlet $\left(\mathrm{u}_{\mathrm{f}}\right)$ and mean grain diameter $\left(D_{50}\right)$. For training and testing model, experimental data in two forms of original and non-dimensional are selected. The results of this research indicate that MLP/BP model can predict the scour cone volume and length. Finally, sensitivity analysis with original and nondimensional data set show that mean flow velocity through outlet $\left(u_{f}\right)$ and $u_{f} / \sqrt{ }\left(g\left(G_{s}-1\right) D_{50}\right)$ have a greater influence on scour cone volume and length rather than other parameters.

KEYWORDS: pressure flushing, scour cone, MLP/BP ANN model, experimental study, sensitivity analysis.

\section{INTRODUCTION}

The number of dam constructions has increased during the last decades, particularly in the tropics and semi-arid areas where high sediment yields are prominent, and therefore also the problems of reservoir sedimentation (Brandt, 2000). Siltation poses a severe threat to the operability and life time of reservoirs (Francke et al., 2008). For desilting of the deposited sediment in the reservoir many methods can be used. For example these methods are watershed management, dredging, density current venting, and flushing. In flushing methods, the previously deposited sediment would be flushed from the reservoir by opening of the outlets. When the flushing takes place under a sustained water level, only a very limited area in the reservoir is cleared. This is only an option in reservoirs with small reservoir capacity to water inflow, and large capacity of sluices (Qian, 1982). In the pressure flushing (under pressurized flow condition) sediment deposits can be scoured in the vicinity of the sluice-gate opening within a very short period of time. A funnel shaped crater called flushing cone will be formed by the flushing flow. Once the flushing cone has been formed and there is no sediment moving into the cone, the water flowing through the opening is clear, that is the formation of cone is fairly stable and no sediment will be removed from the flushing cone afterward (Di Silvio, 1990). Figure 1 illustrates the schematic diagram of pressure flushing.

The equilibrium of scour cone volume and length, which is typically developed in a reservoirs after pressure flushing, depends on the reservoir water (subscript w) depth $\mathrm{Hw}$, depth of deposited sediment (subscript s) Hs above the intake, fluid density $\rho_{w}$, sediment density $\rho_{S}$, intake diameter $\mathrm{D}_{\mathrm{G}}$, water velocity at intake $\mathrm{u}_{\mathrm{f}}$, fluid dynamic viscosity $\mu$, gravitational acceleration $\mathrm{g}$, and mean grain diameter d50 of non-cohesive sediment. As the equilibrium scour cone volume $V_{f}$ and length $L_{f}$ are basic variables, they are separately expressed as (Fathi-Moghadam et al., 2010): 


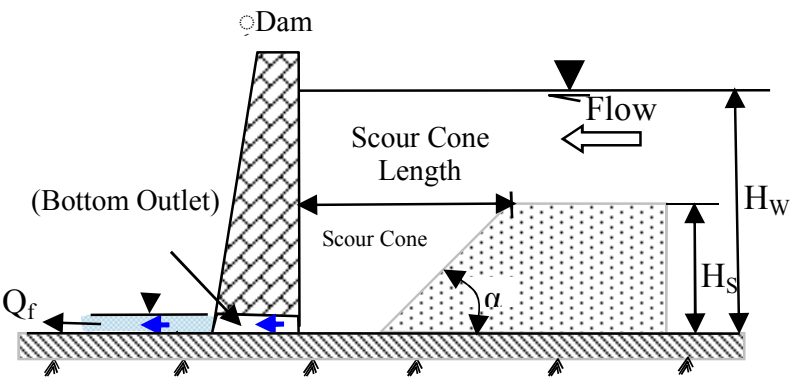

A- Longitudinal profile

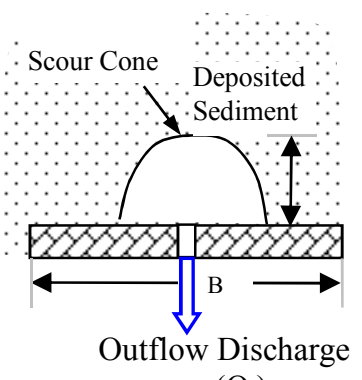

$\left(\mathrm{Q}_{\mathrm{f}}\right)$

B- Plan

Figure 1. Schematic of the scour cone which developed in front of outlet in the pressure flushing: ALongitudinal profile, B- Plan

$$
\begin{aligned}
& V_{f}=f\left(u_{f}, H_{W}, H_{S}, D_{G}, g, \rho_{S}, \rho_{W}, D_{50}, \mu\right) \\
& L_{f}=f\left(u_{f}, H_{W}, H_{S}, D_{G}, g, \rho_{S}, \rho_{W}, D_{50}, \mu\right)
\end{aligned}
$$

Fathi-Moghadam et al. (2010) based on dimensional analysis proposed the following nonlinear equations to estimate the dimensionless flushing cone volume and length:

$$
\begin{aligned}
& \frac{V_{f}^{\frac{1}{3}}}{D_{G}}=k_{V}\left(\frac{u_{f}}{\sqrt{g\left(G_{s}-1\right) D_{50}}}\right)^{a v}\left(\frac{H_{w}}{H_{S}}\right)^{b v} \\
& \frac{L_{f}}{D_{G}}=k_{l}\left(\frac{u_{f}}{\sqrt{g\left(G_{s}-1\right) D_{50}}}\right)^{a l}\left(\frac{H_{w}}{H_{S}}\right)^{b l}
\end{aligned}
$$

where $k_{v}, a_{v}, b_{v}$ and $k_{1}, a_{l}, b_{l}$ are coefficients for scour cone volume (subscript v) and length (subscript I).

In the pressure flushing the flow pattern in the vicinity of the flushing outlets is three dimensional and also due to the high number of parameters involved in the phenomena, analytical treatment of it is difficult (Scheuerlein et al., 2004). Therefore in this study, we propose an alternative methodology to analyze this phenomenon. Artificial Neural Network (ANN) can efficiently tackle the lack of linearity and the multivariate reservoir flushing behavior, even when the underlying interrelationships of the variables are unknown (Jain and Chalisgaonkar, 2000). So far artificial neural network (ANN) is becoming effective tool for providing hydraulic and environmental engineers with more accuracy for design purposes and management practices (Bateni et al., 2007). ANN has been widely applied in various areas of hydraulics and water resources engineering (Muttiah et al., 1997; Zhang et al., 1998; Jain, 2001; Nagy et al., 2002; Li and Gu, 2003; Yitian and Gu, 2003; Agarwal et al., 2005, Azmathullah et al., 2006; Bateni et al., 2007; Muzzammil, 2008).

For example Panagoulia (2006), investigated the ability of artificial neural network models to simulate high and low flows in various climate conditions over a medium-sized mountainous catchment. For this purpose, the author used an algorithm coupling linear least squares and simplex optimization (LLSSIM) for estimating the weights (parameters) of a three-layer ANN. The daily flows in three climatically different periods, described by trends of clearly descending, rising and moderately descending segments in the long-term annual pseudo-precipitation (rain plus melt) of the Mesochora catchment in central Greece for a 15-year period were used. The study showed that the ANN model can simulate high and low flows quite well when it is calibrated for increasing values of pseudo-precipitation and is validated for moderately decreasing values of pseudo-precipitation. Furthermore, for comparison purposes, the author used physically-based conceptual soil moisture accounting (SMA) model of the US NWS. Finally the author stated that since the ANN model has no physically realistic components and parameters, it is by no means a substitute of the SMA model.

Overall, the present study is aimed to evaluate ANN model for the equilibrium scour cone volume and length in front of bottom outlet. 


\section{ARTIFICIAL NEURAL NETWORK (ANN)}

An ANN model is a network of simple units, each having a local memory. These units, known as neurons, are connected by unidirectional links that carry discriminating data (Nagy et al., 2002). Neural network provide a random mapping in between an input and output vector by mimicking the biological cognition process of our brain (Azmathullah et al., 2005). Neurons are defined as mathematical expressions that filter the signal through the net. The net is formed by successive layers of neurons and each neuron is connected to each of the neurons in the previous layer (Caamaño et al., 2006). A multi-layer perceptron (MLP) is a typical ANN consists of a number of nodes that are organized according to a particular arrangement (Figure 2).

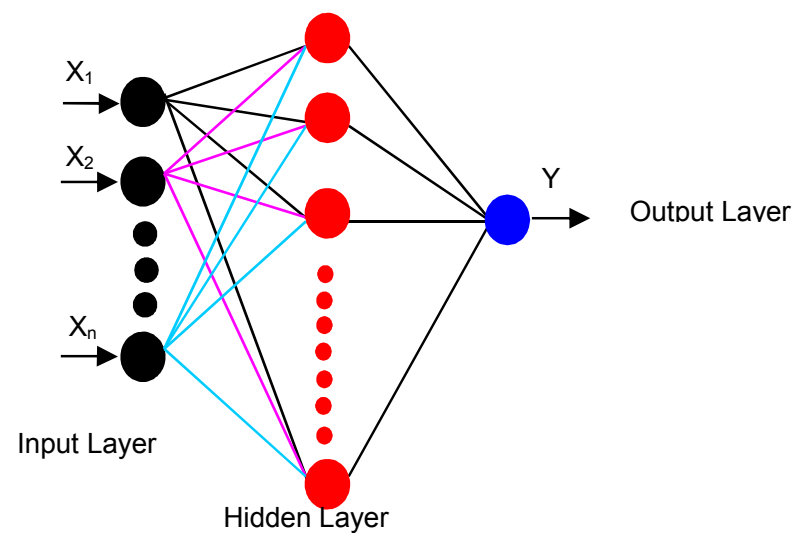

Figure 2. Structure of typical MLP model

The transfer function serves to normalize a node's output signal strength between 0 and 1 . Each node multiplies every input by its interconnection weight, sums the product, and then passes the sum through a transfer function to produce its result. This transfer function is usually a steadily increasing S-shape curve called a sigmoid function. Under this threshold function, the output $\mathrm{y}_{\mathrm{j}}$ from the jth neuron in a layer is (Bateni et al., 2007)

$$
y_{j}=f\left(\sum w_{i j} x_{i}\right)=\frac{1}{1+e^{-\left(\sum w_{i j} x_{i}\right)}}
$$

where $w_{i j}$ is the weight of the connection joining the jth neuron in a layer with the ith neuron in the previous layer and $x i$ the values of the ith neuron in the previous layer. Back propagation is a learning algorithm proposed by Rumelhart et al. (1986). In the Back propagation learning algorithm neural networks process information in interconnecting processing elements (often termed neurons, units or nodes). In order to compare the performance of various ANN configurations two statistical parameters were used in this research. These statistical parameters are the root mean square error (RMSE) and the coefficient of determination, $\mathrm{R}^{2}$, of linear regression line between the predicted values from either the ANN and regression models and the desired output. These parameters are defined as:

$$
\begin{aligned}
& R^{2}=\left(\frac{\sum_{i=1}^{n}\left(X_{i}-Y_{i}\right)^{2}}{\sqrt{\sum_{i=1}^{n} x_{i}^{2} \sum_{i=1}^{n} y_{i}^{2}}}\right)^{2} \\
& R M S E=\sqrt{\frac{\sum_{i=1}^{n}\left(X_{i}-Y_{i}\right)^{2}}{n}}
\end{aligned}
$$

where $x=(X-\bar{X}), y=(Y-\bar{Y}), \mathrm{X}=$ observed values, $\mathrm{Y}=$ Predicted values, $\bar{Y}=$ mean of $\mathrm{Y}, \bar{X}=$ mean of $X$, ' $n$ ' is the number of testing patterns. 


\section{RESULTS AND DISCUSSIONS}

\subsection{Regression models}

For training and testing of regression and ANN models experimental data which used by FathiMoghadam et al., (2010) and Emamgholizadeh (2008) considered for this research. The kind of sediments which used by mentioned researchers was non-cohesive sediment. The ranges of different parameters involved in this study are given in Table 1.

Table 1. Data ranges of the scour cone parameters which used for estimation of equilibrium scour cone volume and length

\begin{tabular}{lcc}
\hline Parameters & Symbol & Range \\
\hline Scour cone volume $\left(\mathrm{m}^{3}\right)$ & $\mathrm{V}_{\mathrm{f}}$ & $0.0002-0.0623$ \\
Scour cone length $(\mathrm{m})$ & $\mathrm{L}_{\mathrm{f}}$ & $0.155-0.648$ \\
reservoir water depth $(\mathrm{m})$ & $\mathrm{H}_{\mathrm{w}}$ & $0.36-1.2$ \\
depth of deposited sediment $(\mathrm{m})$ & $\mathrm{H}_{\mathrm{s}}$ & $0.18-0.42$ \\
water velocity at intake $\left(\mathrm{m} \mathrm{s}^{-1}\right)$ & $\mathrm{u}$ & $0.26-4.08$ \\
\hline
\end{tabular}

The current study used 60 data sets in order to predict equilibrium scour cone volume and length. The whole data was divided into two parts:

- Training data set consisting 45 data and,

- Validation or testing data set consisting of 15 data points.

For statistics analysis, the experimental data sets were used in two forms - (1) original data and (2) non-dimensional data. A linear multiple regression method was used to get the regression parameters of the equilibrium scour cone volume and length prediction models. For this purpose, $75 \%$ of all data was used. Validation of these equations was made with the using of reaming $25 \%$ of the data.

\section{- Original data set}

As it mentioned in the dimensional analysis section, the effective parameters which influence the equilibrium scour cone volume $\left(V_{f}\right)$ and length $\left(L_{f}\right)$ was water depth in the reservoir $(\mathrm{Hw})$, water velocity through outlet $\left(u_{f}\right)$, and the mean grain diameter (d50). Therefore they can be written as the following equations:

$V_{f}=\alpha+\beta u_{f}+\gamma H_{W}+\eta d_{50}$

$L_{f}=\alpha+\beta u_{f}+\gamma H_{W}+\eta d_{50}$

By using linear multiple regression, the value of the parameters $\alpha, \beta, \gamma$ and $\eta$ was achieved $0.04024,0.00683,-0.00793$ and -9.396 for equilibrium scour cone volume $\left(V_{f}\right)$ and $0.519,0.0314$, 0.0259 , and -37.72 for the scour cone length $\left(L_{f}\right)$. Table 2 shows the regression coefficient $\left(\mathrm{R}^{2}\right)$ and RMS Error of equilibrium scour cone volume and length in two stages, (1) training and (2) validation.

Table 2. The results of linear multiple regression models for equilibrium scour cone volume and length for original data set

\begin{tabular}{lllll}
\hline Parameter & \multicolumn{2}{c}{ Scour } & cone volume & \multicolumn{2}{c}{ Scour cone length } \\
\cline { 2 - 5 } Stage & Training & Validation & Training & Validation \\
\cline { 2 - 5 }$\left(\mathrm{R}^{2}\right)$ & 0.89 & 0.73 & 0.91 & 0.53 \\
RMS Error & 0.052 & 0.064 & 0.048 & 0.086 \\
\hline
\end{tabular}


- Non-dimensional data set

Fathi-Moghadam et al. (2010) based on regression analysis proposed the following nonlinear equations to estimate the dimensionless flushing cone volume and length:

$$
\begin{array}{ll}
\frac{V_{f}^{\frac{1}{3}}}{D_{G}}=5.28\left(\frac{u_{f}}{\sqrt{g\left(G_{s}-1\right) D_{50}}}\right)^{0.10}\left(\frac{H_{w}}{H_{S}}\right)^{-0.046} & R^{2}=0.89 \\
\frac{L_{f}}{D_{G}}=8.19\left(\frac{u_{f}}{\sqrt{g\left(G_{s}-1\right) D_{50}}}\right)^{0.10}\left(\frac{H_{w}}{H_{S}}\right)^{-0.033} & R^{2}=0.89
\end{array}
$$

Therefore for non-dimensional data set these equations were used. Validation of these equations was made with the using of reaming $25 \%$ of data, which were not involved in the calculating of coefficients. Table 3 shows $\mathrm{R}^{2}$ and RMS Error of equilibrium scour cone volume and length in two stages, (1) training and (2) validation.

Table 3. The results of linear multiple regression models for equilibrium scour cone volume and length for non-dimensional data

\begin{tabular}{lcccc}
\hline Parameter & \multicolumn{2}{c}{ Scour cone volume } & \multicolumn{2}{c}{ Scour cone } \\
\cline { 2 - 5 } Stage & Training & Validation & Training & Validation \\
\cline { 2 - 5 }$\left(\mathrm{R}^{2}\right)$ & 0.89 & 0.67 & 0.89 & 0.52 \\
RMS Error & 0.053 & 0.072 & 0.065 & 0.0891 \\
\hline
\end{tabular}

\subsection{Development of ANN model}

As it mentioned in previous section, the task of identifying the number of neurons in the input and output layers is normally simple, as it is dictated by the input and output variables considered to model the physical process. The number of neurons in the hidden layer(s) can be determined through the use of trial-and error procedure (Bateni et al., 2007). In this study, two types of MLP/BP models were developed-(1) single hidden-layer ANN models consisting of only one hidden layer and (2) multiple hidden-layer ANN models consisting of multiple hidden layers. The optimal architecture was determined by varying the number of hidden layers, and the best structure was selected. The training of the ANN models was stopped when either the acceptable level of error was achieved or when the number of iterations exceeded a prescribed maximum of 10000 . The learning rate of 0.01 was also used. The models that minimized the error measures described in the previous section (RMSE) and have high $\mathrm{R}^{2}$ were selected as the optimum.

The data how to present for training is one of the most important aspects of ANN model. Often this can be done in more than one way. The best configuration was determined by trial and error methodology (Bateni et al., 2007).

For develop ANN model, two combinations of data were considered as inputs to predict equilibrium scour cone volume and length. These two input combinations were used to see which one leads to better results. Five of nine parameters in equations 1 and 2 namely fluid density, sediment density, fluid dynamic viscosity, outlet diameter, and gravitational acceleration are constant in all experiments.

Therefore, the first combination involves just three of the nine parameters in equations 1 and 2 that includes water depth $\left(H_{w}\right)$, mean flow velocity through outlet $\left(u_{f}\right)$, and main grain diameter $\left(D_{50}\right)$ as the input pattern and the equilibrium scour cone $\left(V_{f}\right)$ and length $\left(L_{f}\right)$ as the output pattern. The second combination includes two non-dimensional parameters of equations 3 and 4 as the input pattern and normalized equilibrium scour volume $\left(V_{f}^{\frac{1}{3}} / D_{G}\right)$ and length $\left(L_{f} / D_{G}\right)$ as the output pattern. Figures.3a and $b$ show the network configuration of MLP/BP that may be used for the prediction of the equilibrium scour cone volume and length for two combinations of input:

(a)- Original data set (raw data)

(b)- Non-dimensional data. 


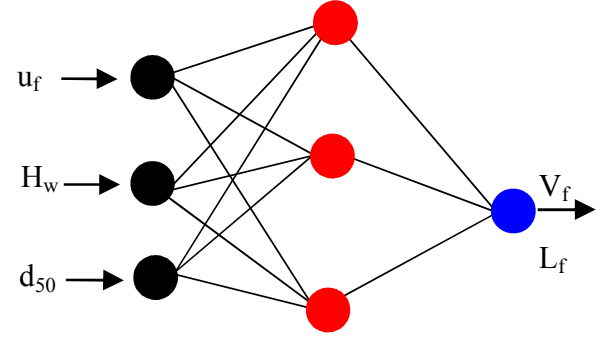

(a) Input Layer Hidden Layer Output Layer

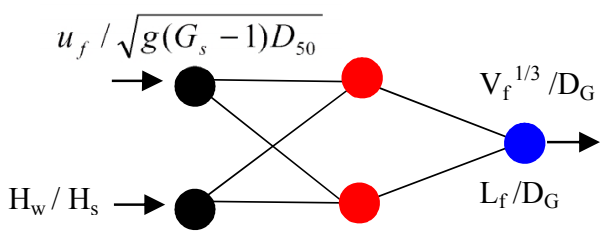

(b) Input Layer Hidden Layer Output Layer

Figure 3. The network for ANN model developed using (a) original data set and (b) non-dimensional data set

\subsection{Equilibrium scour cone prediction using the original data set}

In this section, first original data is used to establish ANN model. As it is mentioned earlier, in the ANN model, the number of hidden layer has direct effect to the results of the model. Therefore in order to investigate the effect of it, the model runs with different hidden layers. As in ANN model which used in the present study, maximum eight hidden layers can be used, therefore the model was run with different hidden layer from 1 to 8 . The model runs with network configuration of Figure 3a for equilibrium scour cone volume $\left(V_{f}\right)$ and length $\left(L_{f}\right)$, separately. For comparison the results of the model, the criteria of RMSE and $R^{2}$ are used. The values of RMSE and $R^{2}$ range from 0.0330.046 and $0.92-0.98$, respectively. The achieved results indicted the MLP configuration that included one hidden layer gave the minimum error and high regression, therefore neural network configuration ( $\begin{aligned} & 3 \\ & 3\end{aligned}$ 1) was selected as the optimum model.

Another parameter which influences the results of the model is the transfer function between the nodes. In order to investigation the effects of it, the model run with different transfer functions including Sigmoid $\left(f(x)=1 /(1+\exp (-x))\right.$, Gaussian $\left(f(x)=e^{-x \cdot x}\right)$, Hyperbolic Tangent $f(x)=\tanh (x))$ and Hyperbolic Secant $(f(x)=\operatorname{Sech}(x))$. The results of the ANN model with different transfer functions are presented in Table 4.

Table 4. The results of the MLP model with different transfer functions for equilibrium scour cone volume and length with original data set

\begin{tabular}{cccccc}
\hline \multirow{2}{*}{$\begin{array}{l}\text { Transfer } \\
\text { Function }\end{array}$} & $\begin{array}{c}\text { Type of } \\
\text { Mode }\end{array}$ & RMS Error & \begin{tabular}{c} 
Regression \\
Coefficient \\
\cline { 3 - 5 } $\mathbf{R}^{\mathbf{2}} \mathbf{n}$
\end{tabular} & RMS Error & $\begin{array}{c}\text { Regression } \\
\text { Coefficient } \\
\mathbf{( R}^{\mathbf{2}} \mathbf{)}\end{array}$ \\
\hline Sigmoid & Training & 0.053 & 0.94 & 0.046 & 0.96 \\
Sigmoid & validation & 0.058 & 0.67 & 0.058 & 0.77 \\
Gaussian & Training & 0.046 & 0.96 & 0.033 & 0.98 \\
Gaussian & validation & 0.049 & 0.75 & 0.039 & 0.87 \\
Hyper. Tan. & Training & 0.052 & 0.95 & 0.056 & 0.94 \\
Hyper. Tan. & validation & 0.059 & 0.66 & 0.042 & 0.69 \\
Hyper. Sec. & Training & 0.054 & 0.94 & 0.054 & 0.94 \\
Hyper. Sec. & validation & 0.051 & 0.68 & 0.066 & 0.65 \\
\hline
\end{tabular}

As the results of Table 4 shows the MLP model has very small RMSE during training (ranging from 0.0033 to 0.049 ). The results of the model show consistently good correlation throughout the training and testing ( $>0.93$ for all models). In overall, the training and validation results of the MLP model with different transfer functions (Sigmoid, Gaussian, Hyperbolic Tangent and Hyperbolic Secant), show that the Gaussian transfer function gives a little bit better results than the other functions. To assess the performance of the ANN model, observed equilibrium scour cone volume and length values are plotted against the predicted ones. Figures $4 a$ and $b$ illustrate the results with the performance indices between predicted and observed data for the training and testing data sets, 
respectively. As it can be seen from the Figures $4 a$ and b, MLP has performed well in predicting the equilibrium scour cone volume and length.
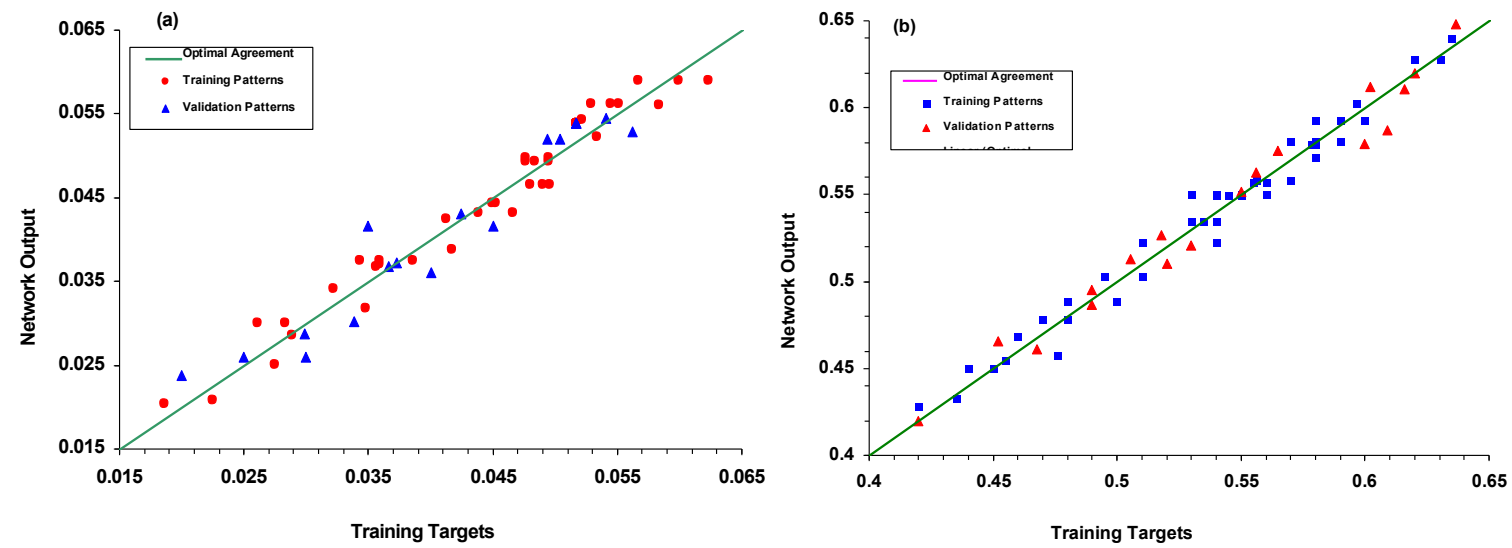

Figure 4. Scatter plots comparing observed and predicted equilibrium scour cone volume (a) and length (b) with original data set using MLP model with Gaussian transfer function for training and validation patterns

\subsection{Equilibrium scour cone volume $\left(V_{f}\right)$ and Length $\left(L_{f}\right)$ prediction using non-dimensional data set}

When network with different input combinations are compared, the training and testing accuracy may be vary significantly. In order to investigate the effect of it, the ANN model runs with the second data set (non-dimensional data set).

As the transfer function and number of hidden layers has effect on accuracy of the model, therefore similar with original data set, model run with different options. The results comparison of ANN model with different transfer functions and multi hidden layers (from 1 to 8 ) show that, the ANN model with Gaussian transfer function and one hidden layer can predict better than other transfer functions and hidden layer. Table 5 show the training and validation results for the MLP model with Gaussian transfer, for the second data set.

Table 5. The results of the MLP model for equilibrium scour cone volume and length (with nondimensional data set)

\begin{tabular}{|c|c|c|c|c|c|}
\hline \multirow[t]{2}{*}{$\begin{array}{l}\text { Transfer } \\
\text { Function }\end{array}$} & \multirow[t]{2}{*}{$\begin{array}{l}\text { Type of } \\
\text { Mode }\end{array}$} & \multicolumn{2}{|c|}{$\begin{array}{c}\text { Non-dimensional scour } \\
\text { cone volume } \\
\left(V_{f}^{\frac{1}{3}} / D_{G}\right)\end{array}$} & \multicolumn{2}{|c|}{$\begin{array}{c}\text { Non-dimensional } \\
\text { scour cone length } \\
\left(L_{f} / D_{G}\right)\end{array}$} \\
\hline & & RMS Error & $\mathbf{R}^{2}$ & RMS Error & $\mathbf{R}^{2}$ \\
\hline Gaussian & Training & 0.0443 & 0.965 & 0.03095 & 0.968 \\
\hline Gaussian & validation & 0.0482 & 0.954 & 0.037 & 0.957 \\
\hline
\end{tabular}

Figure 5 shows the plotted of observed and predicted equilibrium scour cone volume $\left(V_{f}\right)$ and length $\left(\mathrm{L}_{\mathrm{f}}\right)$ with non-dimensional data set using MLP model with Gaussian transfer function for training and validation patterns.

\section{SENSITIVITY ANALYSIS}

Sensitivity tests were conducted to determine the relative significance of each of the independent parameters (input neurons) on the equilibrium scour cone volume and length (outputs). Parameters of water depth $\left(H_{w}\right)$, mean flow velocity through outlet $\left(u_{f}\right)$, and mean grain diameter $\left(D_{50}\right)$ were considered in sensitivity analysis. Table 6 shows the comparison the neural network models, with one of the independent parameters removed in each case. Furthermore Figures $6 a$ and $b$ show the percentage contribution of the independent variables of establishing the ANN model for the equilibrium scour cone volume and length, respectively. 

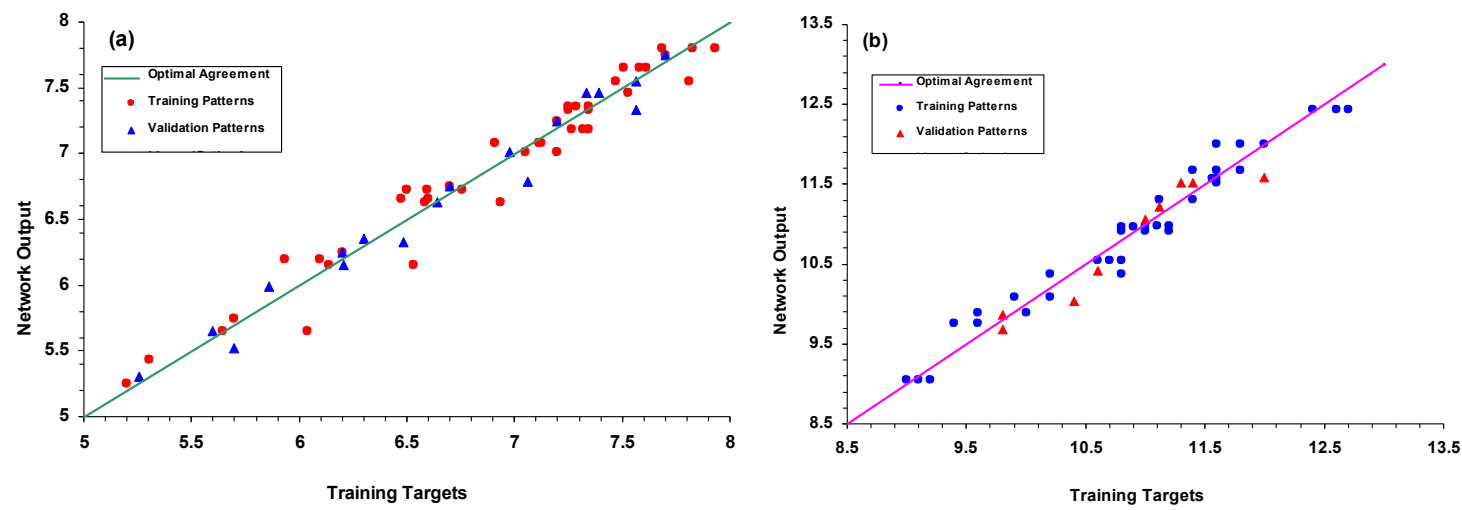

Figure 5. Scatter plots comparing observed and predicted equilibrium scour cone volume (a) and length (b) with non-dimensional data set using MLP model with Gaussian transfer function for training and validation patterns

The results in Table 6 and also in Figures $6 a$ and $b$ show when ANN model run without $U_{f}$, the RMS Error of scour cone volume and length achieved 0.145 and 0.154 and also the regression coefficient achieved 0.41 and 0.508 . In other word the ANN model without Uf rather than other options such as has ANN model without $\mathrm{Hw}$ and $\mathrm{d}_{50}$ has high RMS Error and low regression coefficient. Therefore the mean water velocity through outlet $\left(\mathrm{u}_{\mathrm{f}}\right)$ has the most significant effect on equilibrium scour cone volume and length. The effects of the variables on the equilibrium scour cone volume and length, can be ranked (from higher to lower) in the order $u_{f}, H_{W}$ and $d_{50}$.

Table 6. Sensitivity analysis of the parameters for original data set

\begin{tabular}{ccccc}
\hline \multirow{2}{*}{ Method } & \multicolumn{2}{c}{ Scour cone volume } & \multicolumn{2}{c}{ Scour cone length } \\
\cline { 2 - 5 } & RMS Error & $\mathbf{R}^{\mathbf{2}}$ & RMS Error & $\mathbf{R}^{\mathbf{2}}$ \\
\hline ANN (equations 1 and 2) & 0.043 & 0.976 & 0.033 & 0.966 \\
ANN no. Uf & 0.145 & 0.41 & 0.154 & 0.508 \\
ANN no. Hw & 0.054 & 0.83 & 0.0484 & 0.81 \\
ANN no. $d_{50}$ & 0.043 & 0.87 & 0.0438 & 0.89 \\
\hline
\end{tabular}
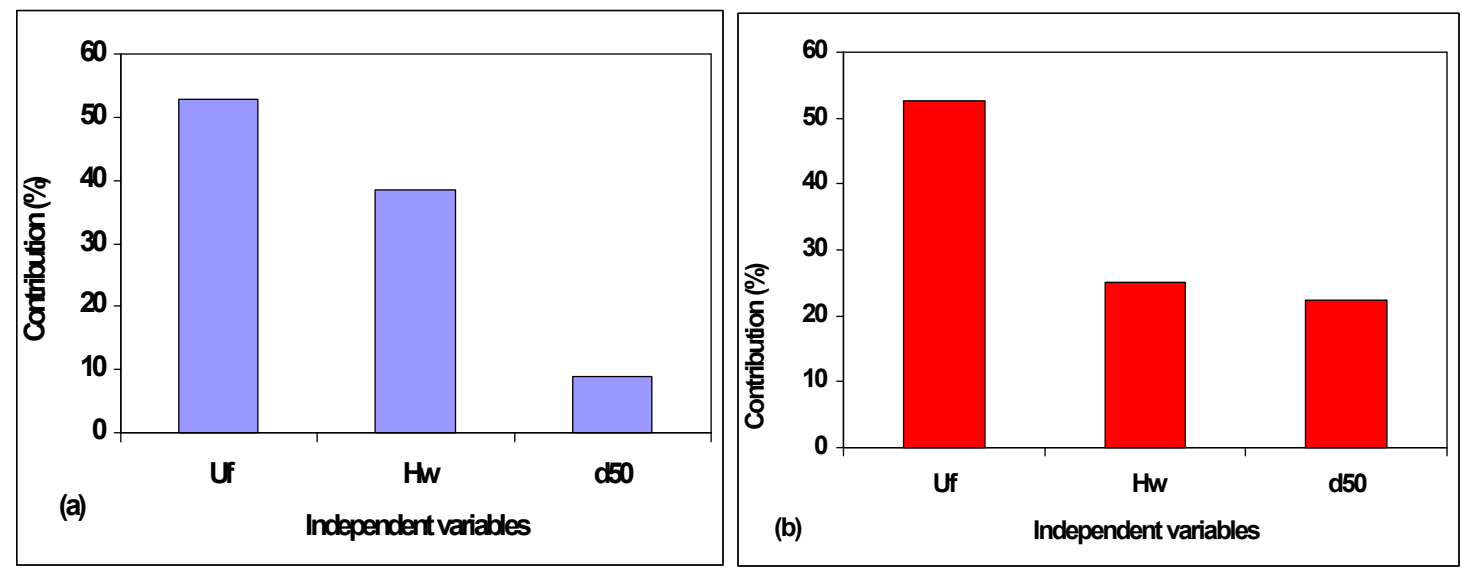

Figure 6. Sensitive analysis of the independent variables for determining the percentage contribution (with original data set) $(a)-V_{f}$ and $(b)-L_{f}$

Similarly, Table 7 gives sensitivity analysis results of the parameters $u_{f} / \sqrt{g\left(G_{s}-1\right) D_{G}}$ and $H_{w} / H_{S}$ on scour cone geometry. As the results in Table 7 show $u_{f} / \sqrt{g\left(G_{s}-1\right) D_{G}}$ and $d_{50} / D_{G}$ have the most and the least effect on equilibrium scour cone volume $\left(V_{f}\right)$ and length $\left(L_{f}\right)$, respectively. This results same to result of Fathi-Moghadam et al., 2010. Their sensitivity analysis by SPSS showed that the $u_{f} / \sqrt{g\left(G_{s}-1\right) D_{50}}$ was the main independent parameters. 
Table 7. Sensitivity analysis of the parameters for non-dimensional data set

\begin{tabular}{lcccc}
\hline \multirow{2}{*}{ Method } & \multicolumn{2}{c}{$V_{f}^{\frac{1}{3}} / D_{G}$} & \multicolumn{2}{c}{$L_{f} / D_{G}$} \\
\cline { 2 - 5 } & $\boldsymbol{R M S ~ E r r o r}$ & $\boldsymbol{R}^{2}$ & $\boldsymbol{R M S}$ Error & $\boldsymbol{R}^{2}$ \\
\hline ANN (equations 3 and 4) & 0.0443 & 0.965 & 0.03095 & 0.968 \\
ANN no. $\left(u_{f} / \sqrt{\left.g\left(G_{s}-1\right) D_{G}\right)}\right.$ & 0.1393 & 0.502 & 0.1533 & 0.453 \\
ANN no. $\left(H_{w} / H_{S}\right)$ & 0.044 & 0.962 & 0.0477 & 0.961 \\
\hline
\end{tabular}

\section{CONCLUSIONS}

In this paper, the application of the ANN model namely, multi-layer perceptron (MLP/BP) and regression models in the estimation of equilibrium scour cone volume and length around the outlet in the pressure flushing has been outlined. The study includes the manipulation of the collected laboratory data to train and to validate the network. It shows that the neural network approach predict equilibrium scour cone volume and length. The selection of input variables to the network has impact on the model accuracy; therefore, based upon dominant parameters, two combinations of them; original and non-dimensional data set were used for the analysis of network. The MLP network with one hidden layerwas selected as the optimum network to predict equilibrium scour cone volume and length. Comparison the results of MLP with different transfer functions (Sigmoid, Gaussian, Hyperbolic Tangent and Hyperbolic Secant) illustrates that the Gaussian transfer function was better than the mentioned transfer functions. Comparing the established regressions and ANN models with using two data set (original and non-dimensional) shows that the ANN model can predict the equilibrium scour cone volume and length better than the regressions models (tables 2 and 3). Also with respect to the criteria of RMS Error and $\mathrm{R}^{2}$ the comparing the established ANN models with two data set show that the established ANN model for non-dimensional data is better than original set (tables 4 and 5). Moreover when data used as non-dimensional form, it can be neglect the model scale, therefore using data with this form recommended for ANN model.

In the pressure flushing, removing of deposited sediment depend on many parameters such as mean flow velocity through outlet, water depth and mean grain diameter. The Sensitivity analysis demonstrated that the mean velocity through outlet $\left(\mathrm{u}_{\mathrm{f}}\right)$ has the most significant effect on equilibrium scour cone volume and length rather than other parameters such as water depth $\left(H_{w}\right)$ and mean grain diameter $\left(D_{50}\right)$. Because the mean velocity through outlet represents the role of outflow discharge $\left(Q_{f}\right)$ and size of outlet $\left(D_{G}\right.$, diameter of outlet) which these parameters has main effect to the geometry of flushing cone. Also, Sensitivity analysis show that $\left(u_{f} / \sqrt{g\left(G_{s}-1\right) D_{G}}\right)$ is the most influential parameter on $\left(V_{f}^{\frac{1}{3}} / D_{G}\right)$ and $\left(L_{f} / D_{G}\right)$.

\section{REFERENCES}

Agarwal A., Singh R.D., Mishra S.K. and Bhunya P.K., (2005), ANN-based sediment yield river basin models for Vamsadhara (India), Water SA, 31(1), 95-100.

Azmathullah H.M., Deo M.C. and Deolalikar P.B., (2005), Neural network for estimation of scour downstream of a ski-jump bucket, Journal of Hydraulic Engineering, 131(10), 898-908.

Azmathullah H.M., Deo M.C. and Deolalikar P.B., (2006), Estimation of scour below spillways using neural networks, Journal of Hydraulic Research, 44(1), 61-69.

Bateni S.A., Borghei S.M. and Jeng D.S., (2007), Neural network and neuro-fuzzy assessments for scour depth around bridge piers, Journal of Engineering Applications of Artificial Intelligence, 20, 401-414.

Brandt S.A., (2000), A review of reservoir desiltation, International Journal of Sediment Research, 15, 321-342.

Caamaño D., Goodwin P. and Manic M., (2006), Derivation of a bedload sediment transport formula using artificial neural networks, 7th International Conference on Hydroinformatics, HIC 2006, Nice, FRANCE, 1-8.

Di Silvio G., (1990), Modeling desiltation of reservoirs by bottom-outlet flushing. NATO Workshop on Movable Bed Physical Models, De Voorst (The Netherlands), August 18-21, 1987. Also in NATO AsiSeries C n. 313, Kluwer Academic Publisher, Dordrecht, 159-171.

Emamgholizadeh S., (2008), Pressure flushing of sediment through storage reservoir: Laboratory 
testing, Journal. Inst. Eng. (India), CE Div. 89(5), 23-27.

Fathi-Moghadam M., Emamgholizadeh S., Bina M. and Ghomeshi M., (2010), Physical modeling of pressure flushing for desilting of non-cohesive sediment, Journal of Hydraulic Research, 48(4), 509514.

Francke T., Mamede G., López-Tarazón J.A. and Batalla R.J., (2008), Assessment of sediment yield and reservoir siltation using non-parametric regression and numerical modeling, Geophysical Research Abstracts, 10, EGU2008-A-06723.

Jain S.K. and Chalisgaonkar D., (2000), Setting up stage-discharge relations using ANN, Journal of Hydrologic Engineering, 5(4), 428-433.

Jain S.K., (2001), Development of integrated sediment rating curves using ANNs, Journal of Hydraulic Engineering, 127(1), 30-37.

Li Y.T. and Gu R.R., (2003), Modeling flow and sediment transport in a river system using an artificial neural network, Environmental Management , 31(1), 122-134.

Muzzammil M., (2008), Application of neural networks to scour depth prediction at the bridge abutments, Journal of Engineering Applications of Computational Fluid Mechanics, 2(1), 30-40.

Muttiah R.S., Srinivasan R. and Allen P.M., (1997), Prediction of two-year peak stream discharges using neural networks, Journal of the American Water Resources Association, 33(3), 625-630.

Nagy H.M., Watanabe K. and Hirano M., (2002), Prediction of sediment load concentration in rivers using artificial neural network model, Journal of Hydraulic Engineering, 128(6), 588-595.

Panagoulia D., (2006), Artificial neural networks and high and low flows in various climate regimes, Hydrological Sciences Journal, 51(4), 563-587.

Qnet's Manual. (2000), Neural Network Modeling for Windows 95/98/NT. Vesta Services, Inc.Winnetka, IL, United States of America.

Qian N., (1982), Reservoir sedimentation and slope stability, technical and environmental effects. Fourteenth International Congress on Large Dams, Transactions, Rio de Janeiro, Brazil, 3-7 May, 3, 639-690.

Rumelhart D.E., Hinton G.E. and Williams R.J., (1986), Learning Internal Representation by Error Propagation, Parallel Distributed Processing, MIT Press, Cambridge, MA, 1, 318-362.

Scheuerlein H., Tritthart M. and Nunez Gonzalez F., (2004), Numerical and physical modeling concerning the removal of sediment deposits from reservoirs, Conference proceeding of Hydraulic of Dams and River Structures, Tehran, Iran 245-254.

Shen H.W. and Lai J.S., (1996), Sustain reservoir useful life by flushing sediment, International Journal of sediment Research, IRTCES, 11(3), 10-17.

Yitian L. and Gu R.R., (2003), Modeling flow and sediment transport in a river system using an artificial neural network, Journal of Environmental Management, 31(1), 122-134.

Zhang G., Patuwo B.E. and Hu M.Y., (1998), Forecasting with artificial neural networks: The state of Art, International Journal of Forecasting , 14(1), 35-62. 